\title{
Diurnal Variations of Endogenous Steroids in the Follicular Phase of the Menstrual Cycle
}

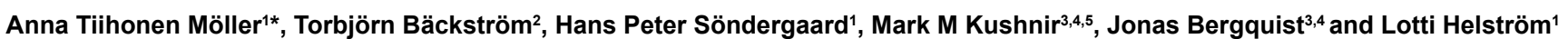

${ }^{1}$ Department of Clinical Science and Education, Karolinska Institutet, Department of Obstetrics and Gynecology,Stockholm South Hospital, Stockholm, Sweden ${ }^{2}$ Department of Clinical Science, Obstetrics and Gynecology, Umeå University, Umeå, Sweden

${ }^{3}$ Department of Chemistry - Biomedical Centre, Analytical Chemistry and SciLifeLab, Uppsala University, Uppsala, Sweden

${ }^{4}$ Department of Pathology, University of Utah, Salt Lake City, USA

${ }^{5}$ ARUP Institute for Clinical and Experimental Pathology, Salt Lake City, USA

\begin{abstract}
Rationale: The diurnal variations of cortisol and of other upstream glucocorticoid steroids have been well described. However, diurnal variations of other steroids in the steroid synthesis pathways have not been fully addressed in the literature.

Objective: To explore possible diurnal variations of several endogenous steroids.

Methods: Blood samples were taken every fourth hour during 24 hours in 10 healthy drug naïve pre-menopausal women in the follicular phase of the menstrual cycle. Using the LC-MS/MS technique, serum was analyzed for concentrations of glucocorticoids (cortisol, cortisone, 11-deoxycortisol), androgens (androstenedione, testosterone, DHEA), pregnenes (pregnenolone, 170H-pregnenolone), progestins (progesterone, $17 \mathrm{OH}$-progesterone), and estrogens (estrone, estradiol). The concentration of the anesthetic steroid allopregnanolone was analyzed using the radioimmunoassay (RIA) technique. The blood samples were divided into six time intervals; 02:01-06:00, 06:01-10:00, 10:01-14:00, 14:01-18:00, 18:01-22:00, and 22:01-02:00. Each steroid was tested for possible diurnal variation using repeated measures ANOVA for within-subject variation.
\end{abstract}

Results: All steroids except the estrogens exhibited a significant diurnal variation $(p<0.05)$. Apart from allopregnanolone, all the steroids peaked in concentration at 08:00 (e.g., just after awakening). Allopregnanolone had a flatter curve, its highest concentrations occurring throughout the day and its peak concentrations at about 12:00.

Conclusions: The present study suggests that when assessing concentrations of steroids in the glucocorticoid group and those in the pregnene, androgen, and progestine groups, as well as allopregnanolone, it might be necessary to accounted for a diurnal variation. However, a possible interaction between menstrual-cycle phase and the hypothalamus-pituitary-adrenal (HPA) axis and the diurnal variations of the steroids should be confirmed by future studies.

Keywords: Diurnal variations; Circadian rhythm; Endogenous steroids; Allopregnanolone; Menstrual cycle; Women

\section{Introduction}

Many studies have been conducted assessing biological changes in patients with both somatic and psychiatric conditions. Most studies of posttraumatic stress disorder (PTSD) have focused on the primary stress pathway: the hypothalamus-pituitary-adrenal axis (HPA), which is activated during acute stress. The hypothalamus secretes corticotropin-releasing factor (CRF) which stimulates the pituitary to release adrenocorticotropic hormone (ACTH), resulting in the production of glucocorticoids and other steroids in the adrenal cortex. It is known that the secretion of cortisol is associated with the natural circadian rhythm, and the assessment of cortisol concentrations should be adjusted for the diurnal variation, with peak values in the morning just after awakening [1]. As cortisol is one of the end products of the glucocorticoid biosynthesis pathway, it can be assumed that the biosynthesis of glucocorticoids upstream and other steroids (Figure 1) also are affected by diurnal variations.

Dehydroepiandosterone (DHEA) and its sulfate (DHEAS) are synthesized from cholesterol, via pregnenolone (sulfate) and 17-hydroxypregnenolone, almost exclusively by the adrenals, only $\pm 10 \%$ of plasma DHEA is derived from the gonads [2]. DHEAS is quantitatively the major steroid hormone secreted by the adrenals, and its plasma concentration in young adults is 10 to 20 times the cortisol concentration. DHEAS has a low metabolic-clearance rate, and as a consequence of this, DHEAS is practically constant during the day and night [3]. However, the concentration of DHEA is 500 to 1,000 times lower than that of DHEAS, and studies have shown that DHEA levels show both pulsatile and nyctohemeral variations, in parallel with cortisol and ACTH pulses [4]. DHEA is also a precursor of testosterone and estrone. One could therefore surmise that the concentrations of these steroids also have diurnal variations.

Alterations the in the neuroactive steroid allopregnanolone in PTSD patients have been suggested. Allopregnanolone, another stress steroid, is anesthetic and anxiolytic. It is converted from progesterone by the

*Corresponding author: Anna Tiihonen Möller, Department of Obstetrics and Gynecology, Stockholm South General Hospital, Sjukhusbacken 10, 11883 Stockholm, Sweden, Tel: +4686164670; E-mail: anna.moller@ki.se

Received February 12, 2016; Accepted February 22, 2016; Published February 28, 2016

Citation: Tiihonen Möller A, Bäckström T, Söndergaard HP, Kushnir MM, Bergquist J, et al. (2016) Diurnal Variations of Endogenous Steroids in the Follicular Phase of the Menstrual Cycle. Neurochem Neuropharm Open Access 2: 109.

Copyright: (C) 2016 Tiihonen Möller A, et al. This is an open-access article distributed under the terms of the Creative Commons Attribution License, which permits unrestricted use, distribution, and reproduction in any medium, provided the original author and source are credited. 
Citation: Tiihonen Möller A, Bäckström T, Söndergaard HP, Kushnir MM, Bergquist J, et al. (2016) Diurnal Variations of Endogenous Steroids in the Follicular Phase of the Menstrual Cycle. Neurochem Neuropharm Open Access 2: 109.

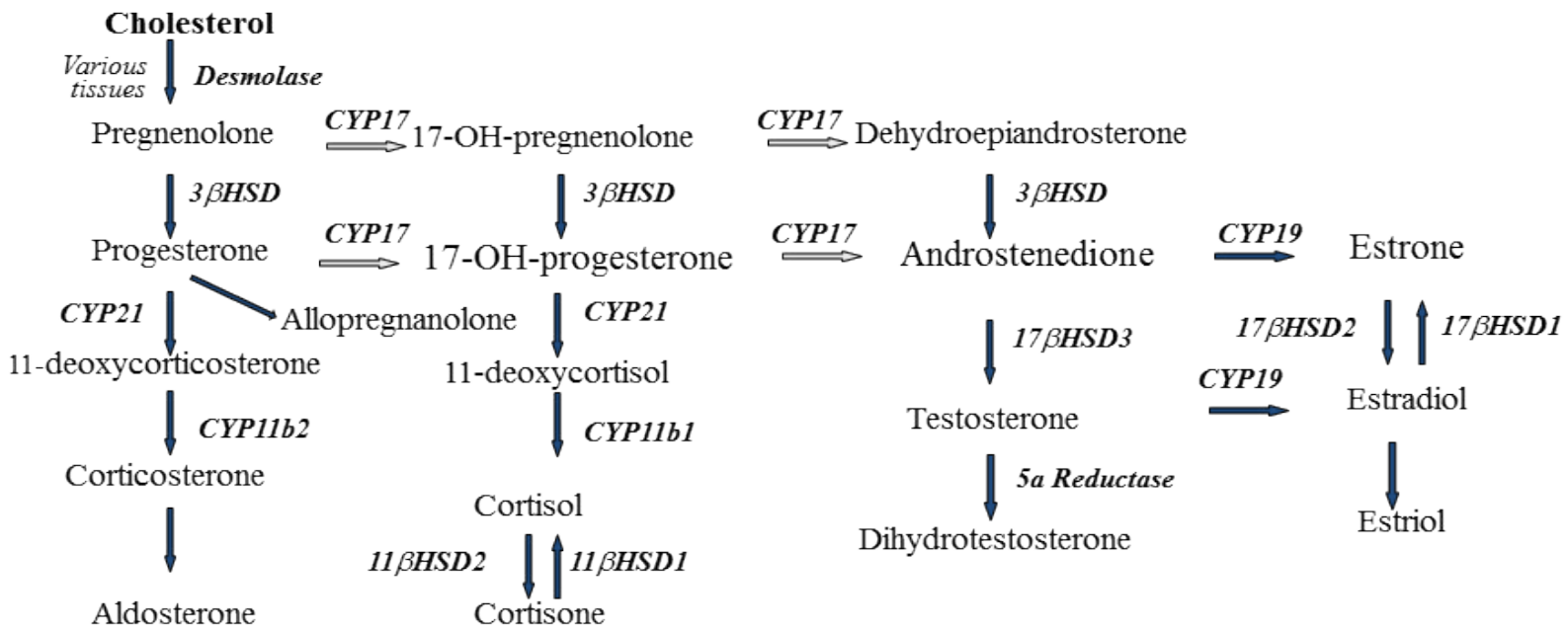

Figure 1: Steroid synthesis pathways

rate-limiting enzyme $5 a$-reductase and has been found at decreased concentrations in cerebrospinal fluid and serum in both patients with PTSD and those with depression [5,6]. It has been determined that allopregnanolone does not manifest a diurnal variation during the luteal phase of the menstrual cycle [7], but there are no reports supporting its diurnal variation during the follicular phase.

Recent studies suggest that alterations occur in steroid concentrations soon after a traumatic event, suggesting that acute biological responses may serve as risk or resilience factors for the development of PTSD. To assess whether an acute response to a trauma is associated with the steroid concentrations, one needs to know whether it is necessary to account for a diurnal variation of that particular steroid.

In this study, concentrations of the steroids were measured using mainly LC-MS/MS techniques, recognized as the best available methodology for the analysis of endogenous steroids [8,9]. Six classes of steroids were measured: anesthetic steroid (allopregnanolone), glucocorticoids (cortisol, cortisone, 11-deoxycortisol), androgens (androstenedione, testosterone, DHEA), pregnenes (pregnenolone, $17 \mathrm{OH}$-pregnenolone), progestins (progesterone, $17 \mathrm{OH}$-progesterone) and estrogens (estrone, estradiol). Concentrations of the steroids were then examined to determine their diurnal variation and their correlation to each other.

\section{Methods}

\section{Participants}

Ten non-traumatized women were recruited through advertisement. Before entering the study, all participants received written and oral information about the study and signed a writtenconsent form. Everyone received a medical screening consisting of a physical examination and a test of thyroid and liver function. The study was approved by the local medical ethics committee in Stockholm (2011/851-31/3).

Inclusion criteria:Women between 18 and 40 years old, who were not taking any hormonal contraceptives or daily medications, and who were physically and mentally healthy were included. Participants had to experience regular menstruations, and all blood sampling was conducted during the follicular phase of their menstrual cycles (days 6-12). Participants had to score low on the Beck Depression Inventory (BDI), the Stanford Acute Stress Reaction Questionnaire (SASRQ), and the Structured Clinical Interview for DSM-IV (SCID-I) interview. These scales are clarified later in this article.

Exclusion criteria: Potential participants were excluded if they had a history of psychosis, major or bipolar depression, alcohol or substance abuse, neurological disease, endocrine disease, polycystic ovarian syndrome (PCOS), premenstrual dysphoric disorder (PMDD) or if they were pregnant. Further, women were excluded if they were smokers or were taking any daily medications, such as antidepressants, anxiolytics, and sedative drugs. Potential participants were also excluded from the study if they reported having taken any benzodiazepines in the three months before the challenge (including any occasional medication) or having consumed alcohol within 72 hours before the blood sampling.

Psychometrics used during inclusion: The Beck Depression Inventory [10] is a 21-item inventory measuring depressive mood and vegetative symptoms of depression. Cut-off points for the sum scores were 0-9 (no depression), 10-16 (mild depression), 17-29 (moderate depression), and $\geq 30$ (severe depression). Participants were allowed to score a maximum of nine points.

The Stanford Acute Stress Reaction Questionnaire, SASRQ [11] is mainly used to diagnose ASD, but in this study it was used as a total score for measuring PTSD symptoms. To be included, participants had to have low scores ( $<10$ out of a possible 150 points). The PTSD Module of the Structured Clinical Interview for DSM-IV (SCID-I) [12] was also used to establish the absence of posttraumatic stress symptoms. Participants had to score zero out of a possible six points.

\section{Procedures}

The study was conducted in a hospital setting, in a room at the Emergency Clinic for Raped Women at Stockholm South General Hospital, Sweden. An intravenous catheter was inserted in the forearm, at a minimum of one hour before the first blood draw. Blood samples were drawn every fourth hour for 24 hours during the follicular phase 
(days 6-12) of the menstrual cycle. On the day of the study, participants followed their daily routines. At night, the intravenous catheter made it possible for the research nurse to take blood samples without interfering with the women's sleep. Participants slept in an ordinary bed in a quiet research room and according to their usual diurnal cycles. The blood samples were collected in two untreated vacutainer tubes. The samples were then centrifuged at 3,200 rpm for 10 minutes. Equal aliquots of serum were then transferred to $2 \mathrm{ml}$ microtubes, labeled with an ID code, and stored at $-70^{\circ} \mathrm{C}$ until transfer on dry ice for analysis.

\section{Steroid analyses}

LS-MS/MS methods: Five classes of steroids were measured using liquid chromatography-tandem mass spectrometry (LC-MS/ MS) technique: glucocorticoids (cortisol, cortisone, 11-deoxycortisol [11DC]), androgens (androstenedione [A4], testosterone [Te], dehydroepiandrosterone [DHEA]), estrogens (estrone [E1], estradiol [E2]), pregnenes (pregnenolone [Pregn], 17OH-pregnenolone [17OHPregn]), and progestins (progesterone [Prog], $17 \mathrm{OH}-$ progesterone [17OHProg]). Te, E1, E2, Pregn, cortisol, cortisone, 17OHPregn, 17OHProg, hydroxylamine, formic acid, trifluoroacetic acid, dansyl chloride and sodium carbonate were purchased from Sigma Chemical Company (St Louis, MO, USA).

A4, DHEA and PROG were purchased from Steraloids Inc. (Newport, RI, USA). The internal standards were deuterium labeled analogues of the steroids $\mathrm{d} 3-\mathrm{Te}$, d3-Pregn, d2-11DC, d9-17OHProg, d3-17OHPregn, d4-F, d3-E, (Cambridge Isotope Laboratories, Andover, MA, USA), d4-E1, and d3-E2 (CDN Isotopes, Toronto, ON, Canada). All other chemicals were of the highest purity commercially available.

Samples were analyzed as previously described [8,13-16]. Briefly, steroids were extracted from samples; DHEA, A4, Te, Pregn, 17OHPregn, 17OHP and Prog were derivatized with hydroxylamine to form oxime derivatives; estrone and estradiol were derivatized with dansyl chloride to form dansyl derivatives. The limit of quantification (LOQ) was $0.05 \mathrm{ng} / \mathrm{mL}$ for Pregn, 17OHProg, and 11DC; $0.25 \mathrm{ng} / \mathrm{mL}$ for 17OHPregn; $1 \mathrm{ng} / \mathrm{mL}$ for Prog; $0.01 \mathrm{ng} / \mathrm{mL}$ for Te and A4; $0.05 \mathrm{ng} /$ $\mathrm{mL}$ for DHEA; and $1 \mathrm{pg} / \mathrm{mL}$ for E1 and E2 [14]. The intra-assay and inter-assay CV were $<8 \%$ and $<11 \%$, respectively $[8,13,14]$. All steroids were analyzed in positive-ion mode using an electrospray ion source on a triple-quadruple mass spectrometer (AB Sciex5500; Foster City, CA, USA). The HPLC system consisted of series 1260 and 1290 HPLC pumps (Agilent Technologies, Santa Clare, USA), and an HTC PAL autosampler (LEAP Technologies, NC, USA) equipped with a fast wash station. The quadruples Q1 and Q3 were tuned to unit resolution, and the mass spectrometer conditions were optimized for the maximum signal intensity of each steroid. Two mass transitions were monitored for each steroid and its internal standard (IS). Quantitative data analysis was performed using Analyst 1.5.2 software. Calibration curves were generated with every set of samples using six calibrators; three quality control samples were included with every set of samples. The Specificity of the analysis in every sample was evaluated by comparing concentrations determined using the primary and the secondary mass transitions [17].

Radioimmunoassay (RIA): The allopregnanolone analysis method has been described in detail elsewhere [18]. Briefly, in this study allopregnanolone was separated from cross-reacting steroids by celite chromatography and thereafter the quantification was made by
RIA using a polyclonal rabbit antiserum raised against 3a-hydroxy20-oxo-5a-pregnane-11-yl-carboxymethyl-ether coupled to bovine serum albumin, provided by RH Purdy, (The Scripps Research Institute, La Jolla, CA, USA) [19]. The rabbit antiserum was used in a dilution of $1 / 5000$. The antibody solution was prepared using $[11,12]$ ${ }^{3} \mathrm{H}$-allopregnanolone, $3 \times 10^{6} \mathrm{cpm} / 32 \mathrm{ml}$ (Perkin-Elmer Life Sciences, Boston, USA) solution containing $65 \mathrm{mM}$ boric acid (Merck) buffer, $\mathrm{pH}=8.0$, bovine serum albumin $100 \mathrm{mg} / \mathrm{ml}$ (Sigma, St Louis, USA), human gamma globulin solution $20 \mathrm{mg} / \mathrm{ml}$ (Octapharma, Sweden), and antibody in a milliliter ratio of the antibody solution: 30:1:1:0.006. The solution was allowed to equilibrate overnight at $8^{\circ} \mathrm{C}$. Antibody solution $(200 \mu \mathrm{l})$ was added to all sample tubes, and the mixture once again was allowed to stand overnight at $8^{\circ} \mathrm{C}$. After the addition of $200 \mu \mathrm{l}$ saturated ammonium sulfate, each tube was again mixed and centrifuged at 20,000 rpm for 20 minutes. Thereafter, the supernatant was aliquoted into a counting vial and diluted with $3.0 \mathrm{ml}$ Optiphase scintillation medium (Wallac, Finland). The samples were counted in a RackBeta (Wallac, Finland) scintillation counter. The sensitivity of the assays was $25 \mathrm{pg}$, with an intra-assay coefficient of variation for allopregnanolone of $6.5 \%$ and an interassay coefficient of variation of $8.5 \%$. The RIA used does not detect the $3 \beta$-epimer (isoallopregnanolone) or the $5 \beta$-epimer (pregnanolone).

\section{Data analyses}

The blood draws were performed six times, once during each of the intervals 02:01-06:00, 06:01-10:00, 10:01-14:00, 14:01-18:00, 18:0122:00, and 22:01-02:00. Mean and standard deviation for each time interval and steroid were calculated. The blood samples were tested for each steroid's diurnal variation using repeated measures ANOVA for within- subject variation. Spearman correlation coefficient was calculated to assess the correlation between concentrations of the steroids. Results were considered significant when the p-value was less than 0.05 . All statistical analyses were conducted using the statistical software version SPSS 22.0.

\section{Results}

\section{Concentrations of steroids at each time interval}

Serum concentrations for each steroid and time interval are listed in Table 1. Concentrations of progesterone in the follicular phase were low, and most samples were below the sensitivity of the assay. Therefore, progesterone was excluded from further analyses.

\section{Diurnal variations}

All steroids, with the exception of estrone and estradiol, had a diurnal variation with significant within-subject variation (see Table 1). Apart from allopregnanolone, all steroids peaked in concentration during time interval 2 (i.e., around 08.00 , just after awakening). For cortisol, cortisone, pregnenolone, 17OH-pregnenolone, DHEA, $17 \mathrm{OH}$-progesterone, and androstenedione, the mean concentration at time interval 2 was significantly higher than the mean concentrations in all the other time intervals.

Allopregnanolone exhibited flatter curve then the other steroids did, its highest concentrations occurring in time intervals 2 , 3, and 4 (i.e., between 06:00 and 18:00). The highest serum concentration of allopregnanolone was seen during time interval 3. Serum concentration in time interval 3 was higher than in the rest of the time intervals but not significantly higher than that in time interval 2. Serum concentrations for all steroids during 24 hours are shown in Figures 2-5. 
Citation: Tiihonen Möller A, Bäckström T, Söndergaard HP, Kushnir MM, Bergquist J, et al. (2016) Diurnal Variations of Endogenous Steroids in the Follicular Phase of the Menstrual Cycle. Neurochem Neuropharm Open Access 2: 109.

Page 4 of 6

\begin{tabular}{|c|c|c|c|c|c|c|c|}
\hline & T1 & T2 & T3 & T4 & T5 & T6 & p-value* \\
\hline & 02:01-06:00 & 06:01-10:00 & 10:01-14:00 & 14:01-18:00 & 18:01-22:00 & 22:01-02:00 & \\
\hline Allopregnanolone & $\begin{array}{l}0.102 \\
\pm 0.009\end{array}$ & $\begin{array}{l}0.125 \\
\pm 0.009\end{array}$ & $\begin{array}{l}0.141 \\
\pm 0.014\end{array}$ & $\begin{array}{l}0.125 \\
\pm 0.013\end{array}$ & $\begin{array}{l}0.118 \\
\pm 0.013\end{array}$ & $\begin{array}{l}0.103 \\
\pm 0.012\end{array}$ & 0.001 \\
\hline Cortisol & $\begin{array}{l}67.50 \\
\pm 14.07\end{array}$ & $\begin{array}{l}146.20 \\
\pm 11.67\end{array}$ & $\begin{array}{l}67.90 \\
\pm 6.16\end{array}$ & $\begin{array}{l}76.67 \\
\pm 7.29\end{array}$ & $\begin{array}{l}35.00 \\
\pm 6.68\end{array}$ & $\begin{array}{l}25.40 \\
\pm 4.81\end{array}$ & $<0.001$ \\
\hline Cortisone & $\begin{array}{l}15.40 \\
\pm 1.81\end{array}$ & $\begin{array}{l}27.10 \\
\pm 1.34\end{array}$ & $\begin{array}{l}20.10 \\
\pm 1.20\end{array}$ & $\begin{array}{l}20.70 \\
\pm 1.19\end{array}$ & $\begin{array}{l}13.20 \\
\pm 1.40\end{array}$ & $\begin{array}{l}9.70 \\
\pm 0.97\end{array}$ & $<0.001$ \\
\hline 11-DC & $\begin{array}{l}0.110 \\
\pm 0.051\end{array}$ & $\begin{array}{l}0.215 \\
\pm 0.062\end{array}$ & $\begin{array}{l}0.013 \\
\pm 0.005\end{array}$ & $\begin{array}{l}0.045 \\
\pm 0.031\end{array}$ & $\begin{array}{l}0.002 \\
\pm 0.002\end{array}$ & $\begin{array}{l}0.002 \\
\pm 0.002\end{array}$ & 0.001 \\
\hline Pregnenolone & $\begin{array}{l}1.030 \\
\pm 0.118\end{array}$ & $\begin{array}{l}1.660 \\
\pm 0.119\end{array}$ & $\begin{array}{l}1.060 \\
\pm 0.065\end{array}$ & $\begin{array}{l}1.150 \\
\pm 0.089\end{array}$ & $\begin{array}{l}0.940 \\
\pm 0.060\end{array}$ & $\begin{array}{l}0.780 \\
\pm 0.051\end{array}$ & $<0.001$ \\
\hline 17OH-Preg & $\begin{array}{l}1.160 \\
\pm 0.656\end{array}$ & $\begin{array}{l}3.850 \\
\pm 0.732\end{array}$ & $\begin{array}{l}0.960 \\
\pm 0.158\end{array}$ & $\begin{array}{l}1.260 \\
\pm 0.445\end{array}$ & $\begin{array}{l}0.370 \\
\pm 0.167\end{array}$ & $\begin{array}{l}0.180 \\
\pm 0.076\end{array}$ & $<0.001$ \\
\hline DHEA & $\begin{array}{l}3.47 \\
\pm 0.53\end{array}$ & $\begin{array}{l}5.67 \\
\pm 0.55\end{array}$ & $\begin{array}{l}3.28 \\
\pm 0.35\end{array}$ & $\begin{array}{l}3.46 \\
\pm 0.40\end{array}$ & $\begin{array}{l}2.56 \\
\pm 0.28\end{array}$ & $\begin{array}{l}2.08 \\
\pm 0.17\end{array}$ & $<0.001$ \\
\hline 17OH-Prog & $\begin{array}{l}0.181 \\
\pm 0.03\end{array}$ & $\begin{array}{l}0.302 \\
\pm 0.04\end{array}$ & $\begin{array}{l}0.146 \\
\pm 0.007\end{array}$ & $\begin{array}{l}0.149 \\
\pm 0.020\end{array}$ & $\begin{array}{l}0.121 \\
\pm 0.010\end{array}$ & $\begin{array}{l}0.114 \\
\pm 0.019\end{array}$ & $<0.001$ \\
\hline Testosterone & $\begin{array}{l}0.197 \\
\pm 0.022\end{array}$ & $\begin{array}{l}0.230 \\
\pm 0.018\end{array}$ & $\begin{array}{l}0.187 \\
\pm 0.014\end{array}$ & $\begin{array}{l}0.195 \\
\pm 0.021\end{array}$ & $\begin{array}{l}0.178 \\
\pm 0.008\end{array}$ & $\begin{array}{l}0.185 \\
\pm 0.019\end{array}$ & 0.012 \\
\hline Androstenedione & $\begin{array}{l}0.939 \\
\pm 0.119\end{array}$ & $\begin{array}{l}1.330 \\
\pm 0.164\end{array}$ & $\begin{array}{l}0.866 \\
\pm 0.094\end{array}$ & $\begin{array}{l}0.901 \\
\pm 0.125\end{array}$ & $\begin{array}{l}0.700 \\
\pm 0.070\end{array}$ & $\begin{array}{l}0.700 \\
\pm 0.085\end{array}$ & $<0.001$ \\
\hline Estrone & $\begin{array}{l}0.037 \\
\pm 0.003\end{array}$ & $\begin{array}{l}0.037 \\
\pm 0.004\end{array}$ & $\begin{array}{l}0.033 \\
\pm 0.003\end{array}$ & $\begin{array}{l}0.039 \\
\pm 0.005\end{array}$ & $\begin{array}{l}0.034 \\
\pm 0.003\end{array}$ & $\begin{array}{l}0.037 \\
\pm 0.005\end{array}$ & NS \\
\hline Estradiol & $\begin{array}{l}0.053 \\
\pm 0.010\end{array}$ & $\begin{array}{l}0.054 \\
\pm 0.009\end{array}$ & $\begin{array}{l}0.058 \\
\pm 0.010\end{array}$ & $\begin{array}{l}0.048 \\
\pm 0.010\end{array}$ & $\begin{array}{l}0.045 \\
\pm 0.008\end{array}$ & $\begin{array}{l}0.049 \\
\pm 0.008\end{array}$ & NS \\
\hline
\end{tabular}

Note: Data for progesterone are not listed, as concentrations in follicular phase were below LOQ of the assay. ${ }^{*}$-value regarding within-subject variation for each steroid using repeated measures ANOVA.

Table 1: Concentrations of steroids $(\mathrm{ng} / \mathrm{mL})$ in serum at each time interval. Data presented as mean \pm SEM.

\begin{tabular}{|c|c|c|c|c|c|c|c|c|c|c|}
\hline & 2. & 3. & 4. & 5. & 6. & 7. & 8. & 9. & 10 & 11. \\
\hline 1. Allo & 0.108 & $0.268^{*}$ & $0.409^{\star *}$ & 0.187 & $0.383^{* *}$ & 0.051 & 0.192 & $0.280^{*}$ & -0.061 & 0.083 \\
\hline 2. Cortisol & 1 & $0.902^{* *}$ & $0.650^{\star *}$ & $0.850^{* *}$ & $0.652^{\star *}$ & $0.574^{* *}$ & 0.025 & $0.392^{* *}$ & 0.066 & 0.040 \\
\hline 3. Cortisone & & 1 & $0.648^{\star *}$ & $0.734^{* *}$ & $0.590^{\star *}$ & $0.524^{\star *}$ & 0.056 & $0.385^{\star \star}$ & 0.106 & 0.164 \\
\hline 4. Pregnenolone & & & 1 & $0.711^{* *}$ & $0.744^{* *}$ & $0.661^{\star *}$ & $0.423^{* *}$ & $0.674^{\star *}$ & 0.175 & 0.030 \\
\hline 5. 17OHPreg & & & & 1 & $0.857^{* *}$ & $0.709^{\star *}$ & $0.296^{*}$ & $0.591^{* *}$ & 0.191 & 0.071 \\
\hline 6. DHEA & & & & & 1 & $0.622^{\star *}$ & $0.527^{* *}$ & $0.687^{\star *}$ & 0.081 & 0.026 \\
\hline 7. 17OHProg & & & & & & 1 & $0.545^{\star *}$ & $0.814^{\star *}$ & 0.205 & 0.095 \\
\hline 8. Testoterone & & & & & & & 1 & $0.792^{* *}$ & 0.092 & 0.004 \\
\hline 9. A4 & & & & & & & & 1 & 0.106 & 0.046 \\
\hline 10. Estrone & & & & & & & & & 1 & $0.485^{\star *}$ \\
\hline 11. Estradiol & & & & & & & & & & 1 \\
\hline
\end{tabular}

${ }^{*} \mathrm{p}<0.05 ;{ }^{* *} \mathrm{p}<0.01 ;{ }^{* * *} \mathrm{p}<0.001 ; \mathrm{A} 4:$ Androstenedione

Table 2: Relationships between serum steroid concentrations. Correlation coefficients and the corresponding p-values are given.

\section{Bivariate correlations}

As seen in Table 2, apart from the estrogens, which being correlated only with each other, high correlations occurred between almost all the steroids.

\section{Discussion}

The present study is unique, as it is the first to explore the relationship between concentrations of steroids in the pathway of steroid biosynthesis in reproductive-age women during the follicular phase of the menstrual cycle.

The major findings of the present study were that all measured steroids, with the exception of estrogens, showed a diurnal variation in the follicular phase of the menstrual cycle. For all measured steroids, with the exception of allopregnanolone, peak concentrations were observed around 08:00. Allopregnanolone peaked throughout the day, its highest concentrations occurring around 12.00. Further, we saw correlations between a majority of the steroids.
The finding that almost all steroids have a natural circadian rhythm is interesting and further demonstrates the importance of adjusting for this in studies examining differences in serum concentrations of steroids in certain patient groups when the subjects are pre-menopausal women in the follicular phase of their menstrual cycles. The finding of a diurnal variation in allopregnanolone is interesting because no variation was seen in the luteal phase of the menstrual cycle in patients with PMDD or in controls [7]. This suggests that allopregnanolone is secreted from the adrenals in the follicular phase with a rhythm similar to that of the glucocorticoids, but on a flatter curve. The somewhat different slope on the curve might be caused by the longer biosynthesis pathway to allopregnanolone; however, this should be explored in further studies.

In the study on patients with PMDD [7], both patients and healthy controls had comparable concentrations of cortisol. However, patients with higher concentrations of allopregnanolone displayed blunted nocturnal cortisol levels. The researchers suggested that the 


\section{Diurnal variations}
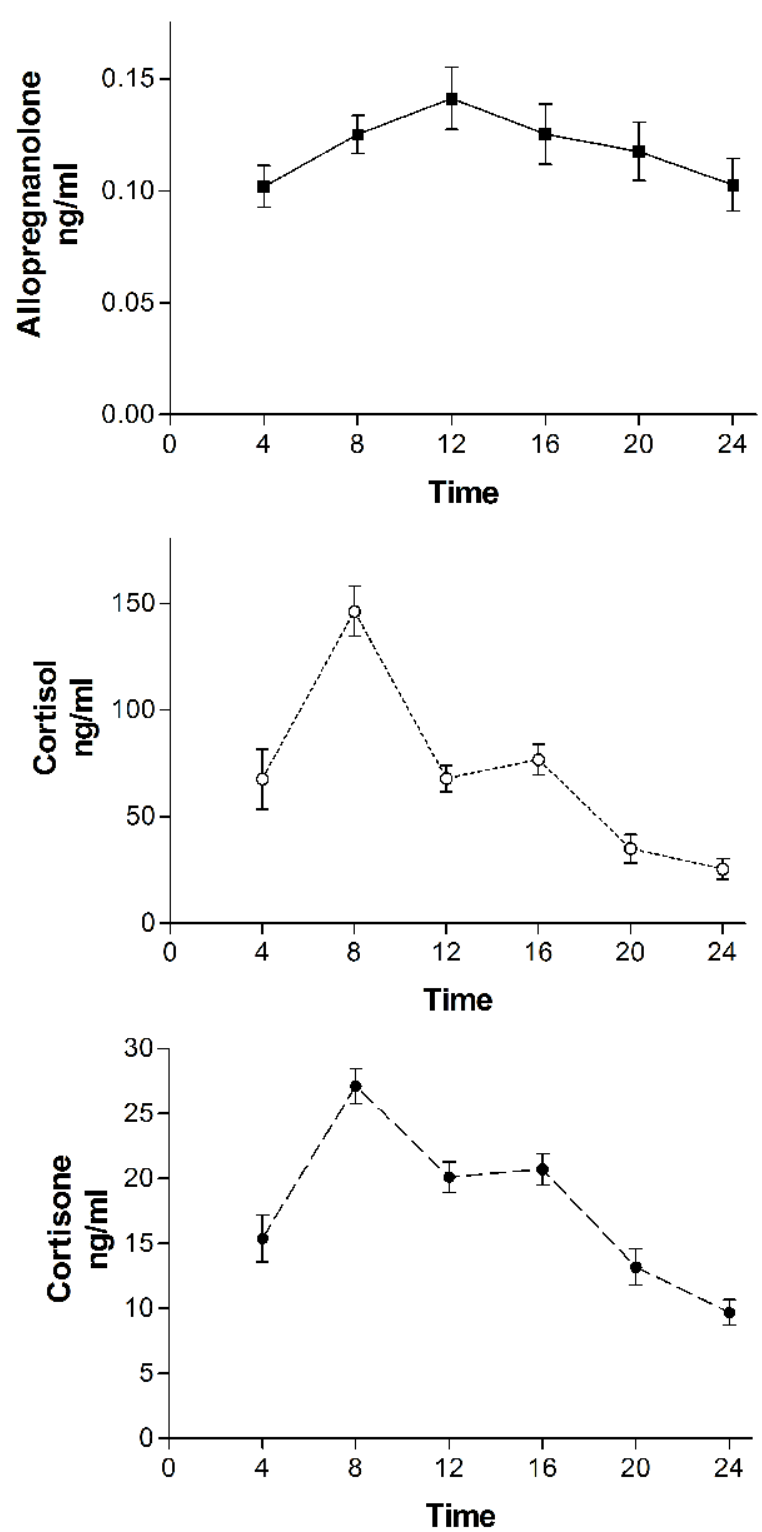

Figure 2: Serum concentrations of allopregnanolone, cortisol, and cortisone during 24 hours presented as mean \pm SEM.

diurnal secretion of cortisol in the luteal phase could be influenced by concentrations of allopregnanolone. Further, they suggested that the timing of blood sampling and individual levels of allopregnanolone could explain the discrepancies in studies examining the HPA axis in PMDD patients. One could assume also that when interpreting the HPA axis in PTSD patients, allopregnanolone concentrations should be considered. Not adjusting for female patients in luteal phase of the menstrual cycle (i.e., when allopregnanolone concentrations are known to be high [20]) could potentially blunt the results. In a recent study, Inslicht et al. [21] discussed difficulties in interpreting neurosteroid responses in pre-menopausal women, suggesting that the reproductive hormones may be involved in modulating the HPA axis.

In the present study all participants were in the follicular phase of the menstrual cycle, and no correlation was seen between allopregnanolone and cortisol $(r=0.108, \mathrm{p}=0.429)$. However, correlations were found between allopregnanolone, pregnenolone, and DHEA and between all steroids (except the estrogens) and androstenedione. Estrone and estradiol correlated with each other but not with any of the other steroids.

\section{Conclusions}

In sum, the present study suggests that just as there is for the glucocorticoids, there is also a natural circadian rhythm to allopregnanolone, the pregnenes, androgens, and progestins in the follicular phase of the menstrual cycle. However, a possible interaction between menstrual-cycle phase and the HPA axis, as well as the diurnal variations of the steroids, should be strengthened with future studies.

\section{Diurnal variations}
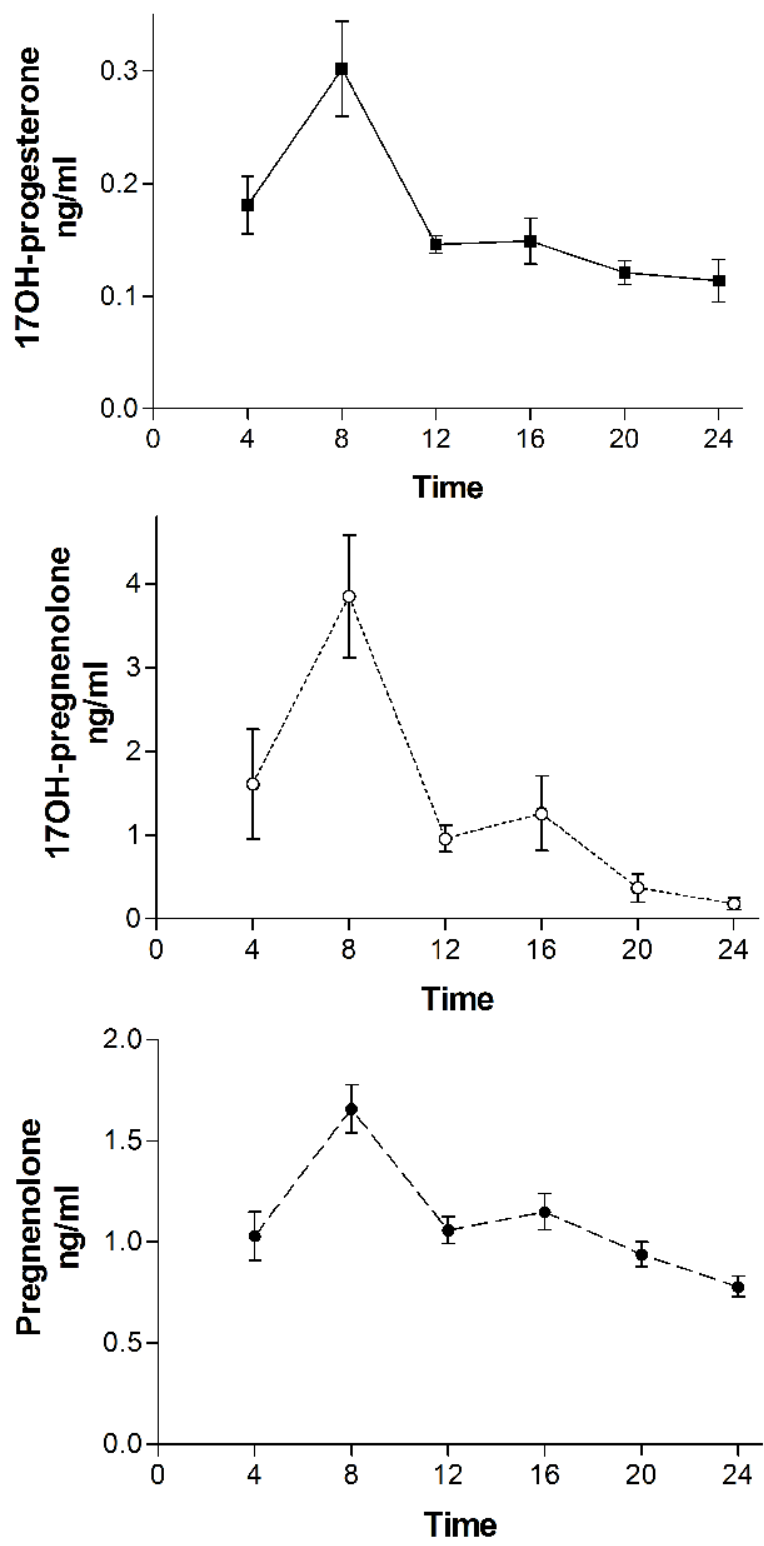

Figure 3: Serum concentrations of $17 \mathrm{OH}$-progesterone, $17 \mathrm{OH}$-pregnenolone and pregnenolone during 24 hours presented as mean \pm SEM. 
Citation: Tiihonen Möller A, Bäckström T, Söndergaard HP, Kushnir MM, Bergquist J, et al. (2016) Diurnal Variations of Endogenous Steroids in the Follicular Phase of the Menstrual Cycle. Neurochem Neuropharm Open Access 2: 109.

Page 6 of 6

\section{Diurnal variations}
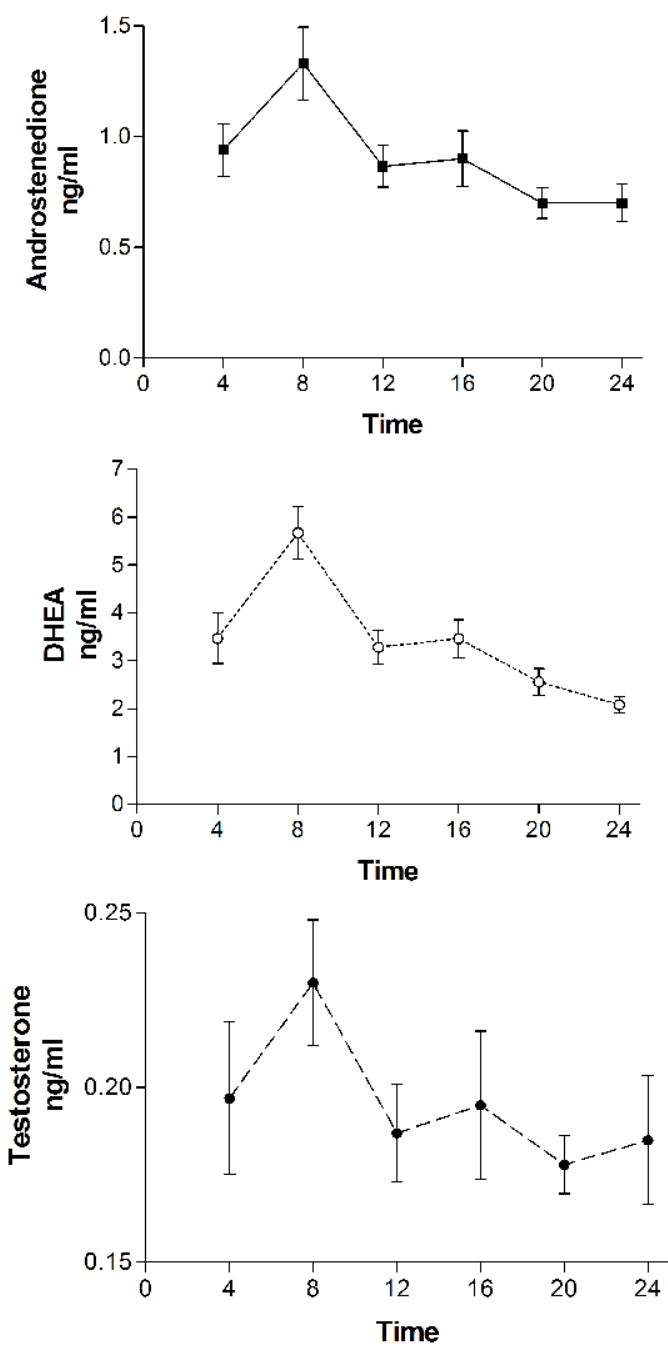

Figure 4: Serum concentrations of androstenedione, DHEA, and testosterone during 24 hours presented as mean \pm SEM.

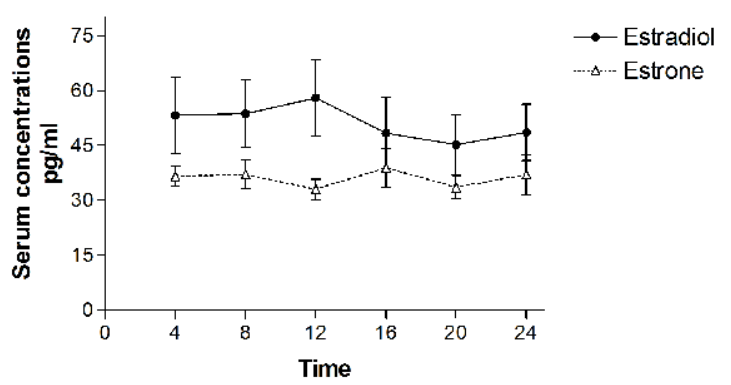

Figure 5: Serum concentrations of estradiol and estrone during 24 hours presented as mean \pm SEM

\section{Acknowledgements}

This study was funded by grants from the Swedish Research Council (Project numbers: 90418601, 621-2011-4423), ALF funding from the Stockholm Council County, the Spearhead Grant, and ALF funding from the Västerbotten County Council, as well as a grant from the Swedish insurance company Folksam, aimed for rape victims. The authors thank the ARUP Institute for Clinical and Experimental
Pathology (Salt Lake City, USA) for supporting this project, and Elisabeth Zingmark for conducting the allopregnanolone assays.

\section{References}

1. Nomura S, Fujitaka M, Sakura N, Ueda K (1997) Circadian rhythms in plasma cortisone and cortisol and the cortisone/cortisol ratio. Clin Chim Acta 266: 8391.

2. Longcope C (1986) Adrenal and gonadal androgen secretion in normal females. Clin Endocrinol Metab 15: 213-228.

3. Thijssen JHH, Nieuwenhuyse H (1999) DHEA: a comprehensive review. London: The Parthenon Publishing Group. pp: 14-21.

4. Rosenfeld RS, Rosenberg BJ, Fukushima DK, Hellman L (1975) 24-Hour secretory pattern of dehydroisoandrosterone and dehydroisoandrosterone sulfate. J Clin Endocrinol Metab 40: 850-855.

5. Rasmusson AM, Pinna G, Paliwal P, Weisman D, Gottschalk C, et al (2006) Decreased cerebrospinal fluid allopregnanolone levels in women with posttraumatic stress disorder. Biol Psychiatry 60: 704-713.

6. van Broekhoven F, Verkes RJ (2003) Neurosteroids in depression: a review. Psychopharmacology (Berl) 165: 97-110.

7. Segebladh B, Bannbers E, Moby L, Nyberg S, Bixo M, et al. (2013) Allopregnanolone serum concentrations and diurnal cortisol secretion in women with premenstrual dysphoric disorder. Arch Womens Ment Health 16: 131-137.

8. Kushnir MM, Rockwood AL, Bergquist J (2010) Liquid chromatography-tandem mass spectrometry applications in endocrinology. Mass Spectrom Rev 29: 480502 .

9. Kushnir MM, Rockwood AL, Roberts WL, Yue B, Bergquist J, et al. (2011) Liquid chromatography tandem mass spectrometry for analysis of steroids in clinical laboratories. Clin Biochem 44: 77-88.

10. Beck A, Brown G (1996) Beck Depression Inventory. (2nd edn). San Antonio: TX: Psycholocical Corp.

11. Cardeña E, Koopman C, Classen C, Waelde LC, Spiegel D (2000) Psychometric properties of the Stanford Acute Stress Reaction Questionnaire (SASRQ): a valid and reliable measure of acute stress. J Trauma Stress 13: 719-734.

12. American Psychiatric Association (2000) Diagnostic and statistical manual of mental disorders. (4th edn). Text Revision (DSM-IV-TR). Washington DC: American Psychiatric Publishing.

13. Kushnir MM, Rockwood AL, Roberts WL, Pattison EG, Owen WE, et al. (2006) Development and performance evaluation of a tandem mass spectrometry assay for 4 adrenal steroids. Clin Chem 52: 1559-1567.

14. Kushnir MM, Rockwood AL, Bergquist J, Varshavsky M, Roberts WL, et al (2008) High-sensitivity tandem mass spectrometry assay for serum estrone and estradiol. Am J Clin Pathol 129: 530-539.

15. Kushnir MM, Blamires T, Rockwood AL, Roberts WL, Yue B, et al. (2010) Liquid chromatography-tandem mass spectrometry assay for androstenedione, dehydroepiandrosterone, and testosterone with pediatric and adult reference intervals. Clin Chem 56: 1138-1147.

16. Kushnir MM, Neilson R, Roberts WL, Rockwood AL (2004) Cortisol and cortisone analysis in serum and plasma by atmospheric pressure photoionization tandem mass spectrometry. Clin Biochem 37: 357-362.

17. Kushnir MM, Rockwood AL, Nelson GJ, Yue B, Urry FM (2005) Assessing analytical specificity in quantitative analysis using tandem mass spectrometry. Clin Biochem 38: 319-327.

18. Timby E, Balgard M, Nyberg S, Spigset O, Andersson A, et al. (2006) Pharmacokinetic and behavioral effects of allopregnanolone in healthy women. Psychopharmacology (Berl) 186: 414-424.

19. Purdy RH, Moore PH, Rao PN, Hagino N, Yamaguchi T, et al. (1990) Radioimmunoassay of 3 alpha-hydroxy-5 alpha-pregnan-20-one in rat and human plasma. Steroids 55: 290-296.

20. Havlikova H, Hill M, Kancheva L, Vrbikova J, Pouzar V, et al. (2006) Serum profiles of free and conjugated neuroactive pregnanolone isomers in nonpregnant women of fertile age. J Clin Endocrinol Metab 91: 3092-3099.

21. Inslicht SS, Richards A, Madden E, Rao MN, O'Donovan A, et al. (2014) Sex differences in neurosteroid and hormonal responses to metyrapone in posttraumatic stress disorder. Psychopharmacology (Berl) 231: 3581-3595. 